\section{Early drusen formation in the normal and aging eye and their relation to age related maculopathy: a clinicopathological study}

\author{
S H Sarks, J J Arnold, M C Killingsworth, J P Sarks
}

\begin{abstract}
Aim-To describe the early formation of drusen and their relation to normal aging changes at the macula and to the development of age related maculopathy (ARM). Method-Histopathological features of 353 eyes without histological evidence of ARM are described and correlated with the clinical appearance. In addition, 45 of these eyes were examined by transmission electron microscopy.
\end{abstract}

Results-Drusen were detected histopathologically in $177(50 \%)$ eyes but were seen clinically in only $34 \%$ of these. Drusen were mainly small hard drusen with an occasional soft distinct drusen: no soft indistinct drusen were seen. Only those drusen deposits larger than $25-30 \mu \mathrm{m}$ in diameter were detectable clinically. Preclinical drusen in eyes with only an occasional drusen were seen on electron microscopy as entrapment sites of coated membrane bound bodies which formed adjacent to the inner collagenous zone of Bruch's membrane. In contrast, preclinical drusen deposits in eyes with many drusen were seen as accumulations of amorphous material which appeared hyalinised by light microscopy. A distinct feature were rows of dense hyalinised microdrusen (1-2 $\mu \mathrm{m}$ in diameter), over which larger globular hyalinised drusen formed.

Conclusion-Histological and ultrastructural examination can recognise and distinguish the earliest drusen formed as a result of normal aging from those associated with ARM. In eyes without diffuse deposits, histologically all drusen were of the hard hyalinised variety or their derivatives; no soft drusen composed of membranous debris were found. These findings support and explain those of other authors who do not consider the presence of a few small hard drusen to be a risk factor for the development of ARM.

(Br f Ophthalmol 1999;83:358-368)

Correspondence to: Dr S H Sarks, 15 Parnell Street, Strathfield, NSW 2135, Australia.

Accepted for publication 1 September 1998 The presence of a few small hard drusen less than $63 \mu \mathrm{m}$ diameter is common and is no longer considered to be a risk factor for the development of age related maculopathy (ARM). The prevalence of drusen in the normal aging population has been addressed by several large population based surveys using graded fundus photography, notably the Chesapeake Bay ${ }^{1}$ and Beaver $\mathrm{Dam}^{2}$ studies in the United States, the Rotterdam study, ${ }^{3}$ and the Blue Mountains study, Australia. ${ }^{4}$ All reported that one or more drusen were found in $95.5-98.8 \%$ of the population, with small hard drusen less than $63 \mu \mathrm{m}$ being the most frequent type in all age groups. While the prevalence of drusen larger than $63 \mu \mathrm{m}$ and soft drusen increases with age, the prevalence of small hard drusen is not related to age or sex. However, drusen of similar appearance may also be found in large numbers and lead to visual loss from geographic atrophy or choroidal neovascularisation (CNV). Since small hard drusen can thus be present in normal eyes without ARM as well as those with ARM, what then is the significance of these drusen, and what is their relation to ARM? In this report we present the clinical and pathological findings in 353 eyes from 202 patients. All eyes on funduscopy were normal or were without soft indistinct drusen, the clinical marker of ARM, and on histopathological examination were without a continuous layer of basal laminar deposit (BLD), the histological hallmark of ARM..$^{5-7}$

Materials and methods

A bank of 616 eyes (364 patients) had been collected from 1967 to 1994 . All the patients (SHS) at 1-3 yearly intervals, the last examination being 2 weeks to 60 months before death (mean 13.9 months). Examination included best corrected visual acuity and direct funduscopy. Fundus photography and, from 1976, fluorescein angiography was carried out where possible using the Zeiss $30^{\circ}$ fundus camera. Only eyes considered on clinical examination to be normal or with age related macular changes were included; excluded were eyes in which the fundus could not be visualised and those with other retinal pathologies including pathological myopia, retinal vascular diseases, patients with mild background retinopathy had been examined clinically by one of us moderate to severe diabetic retinopathy (some 
Table 1 General features of study eyes

\begin{tabular}{llll}
\hline & $\begin{array}{l}\text { Group } 1 \\
\text { No BLD }\end{array}$ & $\begin{array}{l}\text { Group 2 } \\
\text { Patchy BLD }\end{array}$ & Total \\
\hline Number of eyes (patients) & $139(80)$ & $214(122)$ & $353(202)$ \\
Females (\%) & $8(10 \%)$ & $9(7 \%)$ & $17(9 \%)$ \\
Average age (years) & 61.7 & 73.8 & 69.0 \\
Age range (years) & $43-83$ & $60-96$ & $43-96$ \\
Examined EM (number of eyes) & 18 & 27 & 45 \\
\hline
\end{tabular}

$\mathrm{BLD}=$ basal laminar deposit; $\mathrm{EM}=$ electron microscopy.

All eyes in the bank were examined by light microscopy (LM) and over 100 were additionally examined by transmission electron microscopy (EM) by standard techniques. Serial sections $8 \mu \mathrm{m}$ thick were cut horizontally through the macula to include the foveola, optic nerve, and cornea, so that the type, size, and number of drusen outside the macula could also be recorded. Every tenth section was
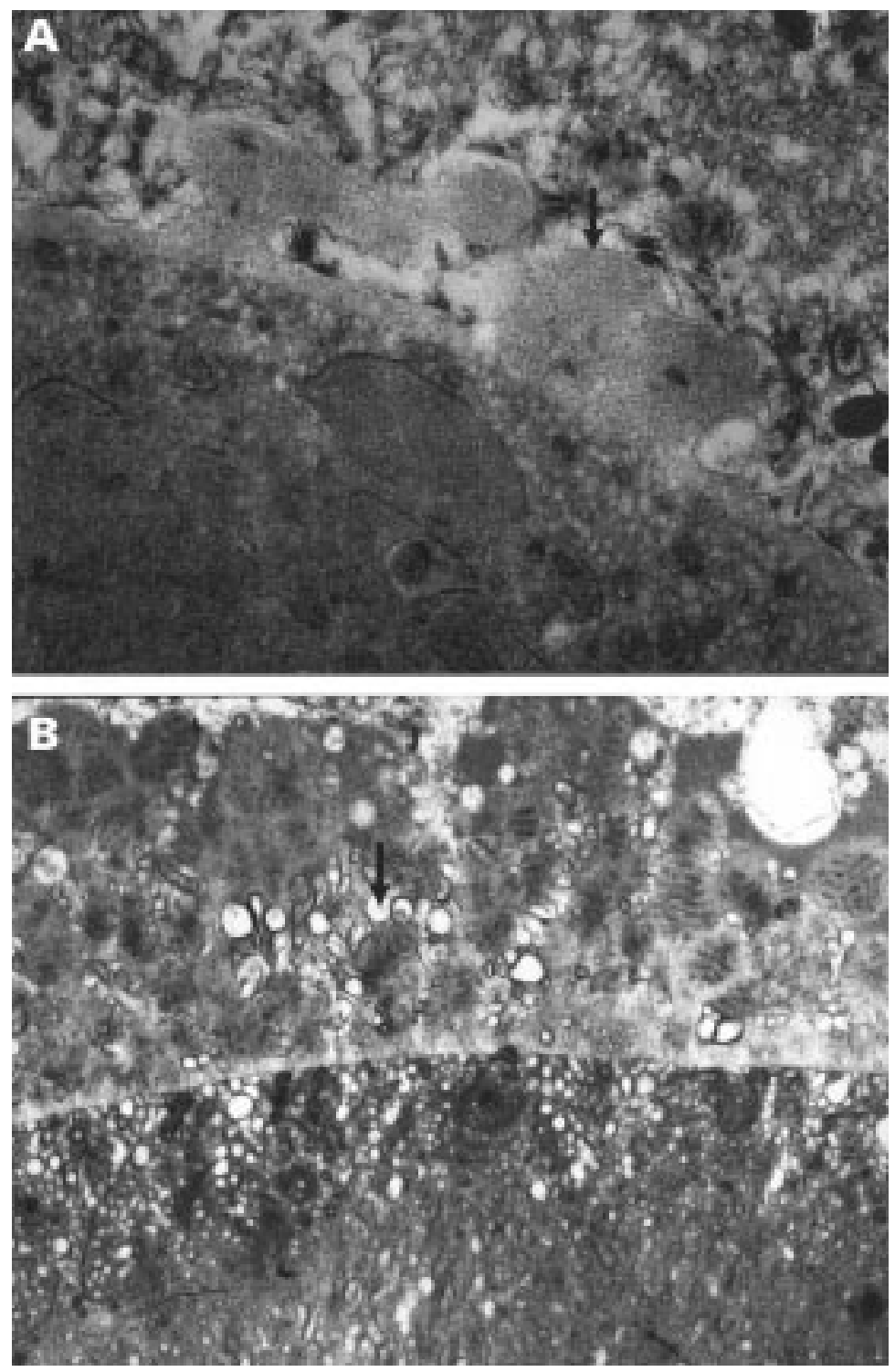

Figure 1 Basal lamina deposit over drusen of mixed composition. (A) Earliest BLD from a group 2 eye consisting of irregular nodules of fibrillar material (arrow) continuous with the RPE basement membrane; there is no membranous debris. (B) In comparison, later BLD seen here in an eye from group 4 consists of fibrillar, amorphous, and long spacing collagen material with a palisading or banded appearance. Membranous debris (arrow) is interspersed between the strands of $B L D$ and within the drusen. (A) $A 56$ year old man with normal fundal appearance, vision 6/6. (B) A 68 year old man with soft indistinct (membranous) drusen and a few small hard drusen, vision 6/6. (A) $\times 21600$ (B) $\times 11400$. stained by the picro-Mallory method with an average of 15 (range 8 to over 40) sections examined per eye. Histopathological findings on some of these eyes have been previously presented. $^{5-10}$ The eyes were divided into six groups depending on the appearance of the $\mathrm{BLD}$, as this reflects the stage of degeneration of the retinal pigment epithelium (RPE). ${ }^{5}$ Briefly, eyes with no BLD (group 1) or those with only patchy BLD (group 2) were considered normal. ARM was diagnosed when the BLD formed a continuous (diffuse) layer beneath the RPE (groups 3 and 4). The end stages of age related macular degeneration, geographic atrophy, and CNV were classed as groups 5 and 6 respectively.

This paper presents the results of the subgroup of 353 eyes of 202 patients defined as normal with no BLD (group 1) or normal aged with only patchy BLD (group 2). Forty five of these eyes were examined by EM.

Bruch's membrane was defined as a trilaminar structure consisting of the inner and outer collagenous zones separated by the elastic layer and excluding the basement membranes of the RPE and the choriocapillaris. ${ }^{11}$ Light microscopic definitions of $\mathrm{BLD},{ }^{12}$ and hard and soft drusen $^{710}$ were used, based on the picroMallory method and periodic acid Schiff (PAS) staining, in conjunction with the international classification for ARM..$^{13}$ BLD was defined on $\mathrm{LM}$ as the material found between the plasma and basement membrane of the RPE, staining blue on the picro-Mallory method. ${ }^{12}$ Hard drusen (nodular drusen ${ }^{7}$ ) have a globular hyalinised appearance, are strongly PAS positive, and stain red with the picro-Mallory method. Soft drusen (accumulation of the basal linear deposit ${ }^{7}$ ) are faintly PAS positive and stain a pale blue with a finely granular or ground glass appearance on the picro-Mallory method. They have sloping edges and, on semithin sections, may appear optically empty. They only occur in the presence of a continuous layer of BLD at the macula. Clinically, the following drusen were defined $^{10}{ }^{13}$ : small hard drusen were $<63 \mu \mathrm{m}$ in diameter with sharply defined borders and early bright hyperfluorescence on fluorescein angiography; soft distinct drusen were $>63 \mu \mathrm{m}$ with solid nodular appearance and distinct edges; soft indistinct drusen were $>63 \mu \mathrm{m}$ with blurred margins, and only faint late hyperfluorescence on fluorescein angiography.

Drusen size was measured on fundus photography using the Wisconsin grid and circle templates designed for use with Zeiss $30^{\circ}$ films. On LM size was estimated using a measuring graticule in the $\times 25$ and $\times 40$ eyepiece objective. The width of one RPE cell (approximately $12-14 \mu \mathrm{m}$ ) was found to be a useful reference. On EM size was calculated from photographs using the known magnification.

\section{Results}

There were 139 eyes in group 1 and 214 in group 2 (see Table 1).

CHANGES IN BRUCH'S MEMBRANE

Thickening and hyalinisation of Bruch's membrane, indicated by a change from blue to red 
Table 2 Comparison of material seen in Bruch's membrane, entrapment sites, and membranous debris

\begin{tabular}{|c|c|c|}
\hline Deposit & Site & Ultrastructural features on EM \\
\hline $\begin{array}{l}\text { Bruch's membrane change } \\
\text { Entrapment sites } \\
\text { Membranous debris }\end{array}$ & $\begin{array}{l}\text { predominantly OCZ } \\
\text { rest on ICZ } \\
\text { raise RPE bm } \\
\text { three sites: } \\
\text { (1) internal to RPE bm } \\
\text { (2) within RPE bm } \\
\text { (3) external to RPE bm } \\
\text { only in presence of BLD }\end{array}$ & $\begin{array}{l}\text { coated membrane bound bodies intact or ruptured } \\
\text { as above } \\
\text { coated membrane bound bodies } \\
\text { coiled membranes } \\
\text { bilayered structure of lipids } \\
\text { not coated }\end{array}$ \\
\hline
\end{tabular}

$\mathrm{EM}=$ transmission electron microscopy; $\mathrm{OCZ}=$ outer collagenous zone of Bruch's membrane; ICZ = inner collagenous zone of Bruch's membrane; RPE bm = basement membrane of the retinal pigment epithelium; BLD = basal laminar deposit.

staining with the picro-Mallory method, was seen in both groups. In the younger eyes (from 40 years old) this appeared focally, ${ }^{5}$ becoming continuous throughout the posterior pole in older eyes. In group 2 eyes the Bruch's membrane changes were more advanced with hyalinisation which reached the base of choroidal capillaries, the capillaries becoming widely spaced between hyalinised pillars of Bruch's membrane. ${ }^{5}$ Patchy basophilia corresponding to calcification was seen in eyes older than 65 years.

Electron microscopy showed that this thickening and hyalinisation of Bruch's membrane was due to the accumulation, predominantly in the outer collagenous zone, of coated membrane bound bodies (CMBB), and of long spacing collagen. These bodies were either intact or ruptured, releasing fragments of degraded membrane, $70 \mathrm{~nm}$ coated vesicle-like bodies, dense granular material, and electron lucent droplets. There was an accompanying increase in native collagen within both the inner and outer collagenous zones.

BASAL LAMINAR DEPOSIT (BLD)

Group 1 (normal) and group 2 (aging) eyes were distinguished histologically by the presence of BLD. Group 1 eyes had no BLD and the RPE was regular. Group 2 eyes had small patches of BLD and the RPE showed an increased amount of lipofuscin. The BLD was located primarily over the apex of small

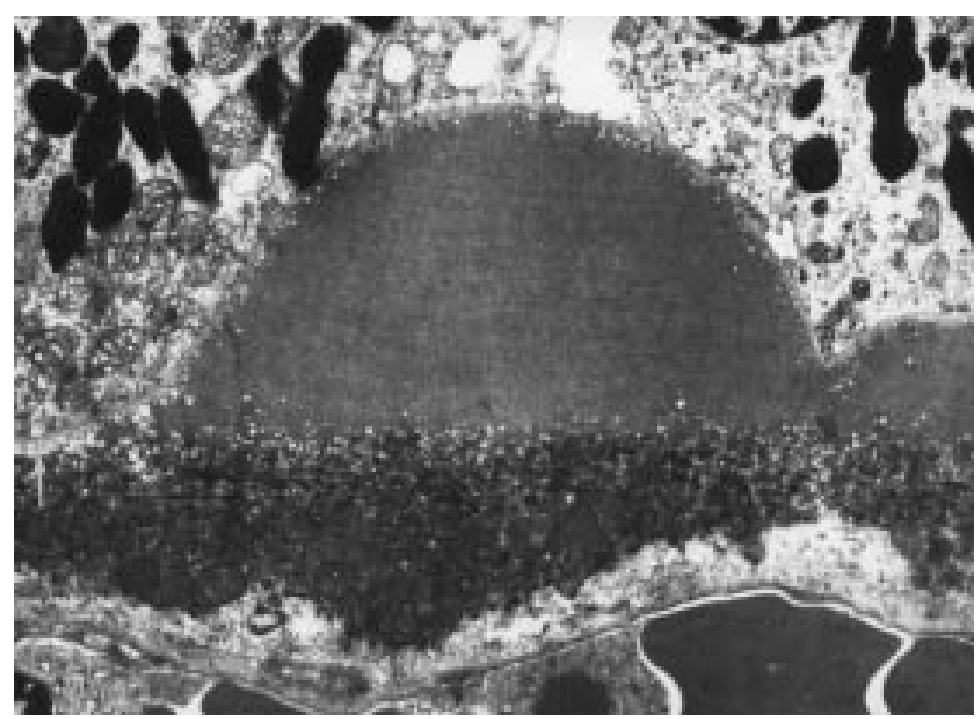

Figure 2 Electron lucent droplets forming a layer three to four rows deep beneath the RPE basement membrane (white arrow) and also beneath and over the apex of a small clinical drusen composed of amorphous material. 79 year old man with normal fundal appearance $\times 6430$. hyalinised drusen (see Figs 8C and 9), best seen on EM, and also over thickened and hyalinised segments of Bruch's membrane. ${ }^{5}$ On LM the BLD stained blue with the picro-Mallory method. On EM the earliest BLD was seen as irregular nodules continuous with the original RPE basement membrane and composed of the predominantly fibrillar form of BLD (Fig 1A) as described by Loeffler and Lee. ${ }^{12}$ At a late stage, BLD is composed of an accumulation of fibrillar, amorphous, and components resembling long spacing collagen (Fig 1B).

A few sparse coiled membranes were also seen in 23 of the 27 group 2 eyes examined by EM, representing the earliest pathological sign of membranous debris. The membranes were only seen in areas where BLD was present and first appeared admixed within the BLD (Fig 1B). These coiled membranes had the bilayered structure of lipids but were much smaller and lacked the membrane coating found on the CMBB of Bruch's membrane described above (see Table 2). They could also be distinguished from the electron lucent droplets which have no limiting membrane, and were found in most eyes aged over 55 years, predominantly beneath the RPE basement but also percolating into the collagenous zones and within the CMBB (Fig 2).

\section{CHOROID}

The choroidal capillaries occupied approximately $70-80 \%$ of a given length beneath the fovea in group 1 eyes with an occasional wide spacing between adjacent choroidal capillaries being occupied by fibrous tissue. In group 2 eyes, capillaries still occupied around $70 \%$ of a given length but were occasionally more widely spaced between hyalinised pillars of Bruch's membrane. A possible macrophage was seen in only two eyes, one beneath and one within a regressing small hard drusen.

DRUSEN

Drusen were detected histopathologically on the sections examined in 177 eyes $(50 \%)$ but were seen clinically in only $34 \%$ of these. Only those drusen deposits larger than $30 \mu \mathrm{m}$ in size, around the diameter of two RPE cells, were detectable on funduscopy, occasionally $25 \mu \mathrm{m}$ on fluorescein angiography; deposits smaller than this are therefore described as preclinical drusen. The drusen detected clinically were all of the small hard variety and in $90 \%$ of eyes were few in number (less than 10). Six eyes, all from patients aged over 70 years, had in addition a few soft distinct drusen. No eye had soft indistinct drusen. Nine eyes of five patients had 
Table 3 Clinicopathological correlation of drusen deposits in 353 eyes with normal aging

\begin{tabular}{|c|c|c|c|c|}
\hline \multirow[b]{2}{*}{ Histopathology of drusen deposits } & \multirow[b]{2}{*}{ Grading * } & \multicolumn{2}{|c|}{ Number of eyes } & \multirow[b]{2}{*}{ Clinical appearance } \\
\hline & & Group 1 & Group 2 & \\
\hline None & - & $80(58 \%)$ & $96(45 \%)$ & normal, no drusen \\
\hline \multirow{2}{*}{$<30 \mu \mathrm{m}$ only (subclinical) } & $<1 / 2$ RPE cell high & 29 & 53 & normal, no drusen \\
\hline & 1/2-1 RPE cell high & 5 & 28 & normal, no drusen \\
\hline \multirow[t]{2}{*}{ At least one $30-63 \mu \mathrm{m}$} & few $1-2$ per section & 15 & 24 & occasional small hard drusen \\
\hline & $\begin{array}{l}\text { moderate }<10 \text { per } \\
\text { section }\end{array}$ & 5 & - & scattered small hard drusen \\
\hline \multirow[t]{3}{*}{ At least one $>63 \mu \mathrm{m}$} & few $1-2$ per section & 3 & 6 & \multirow{4}{*}{$\begin{array}{l}\text { occasional large hard drusen or drusen } \\
\text { cluster } \\
\text { scattered small hard drusen } \\
\text { +occasional large hard drusen (hard } \\
\text { cluster derived drusen) } \\
\text { masses of small hard drusen +hard or } \\
\text { soft distinct drusen }\end{array}$} \\
\hline & $\begin{array}{l}\text { moderate }<10 \text { per } \\
\text { section }\end{array}$ & 2 & 5 & \\
\hline & $\begin{array}{l}\text { significant }>10 \text { per } \\
\text { section }\end{array}$ & & 2 & \\
\hline Total with drusen deposits & & $59(42 \%)$ & $118(55 \%)$ & \\
\hline
\end{tabular}

${ }^{\star}$ Grading: the number of drusen deposits seen on light microscopic serial sections was graded as few (0-2 per section), moderate $(<10$ per section), or significant ( $>10$ per section).

Table 4 Histopathological and ultrastructural features of preclinical drusen deposits

\begin{tabular}{|c|c|c|c|c|}
\hline Deposit type & LM appearance & EM appearance & Size & Clinical correlation \\
\hline $\begin{array}{l}\text { Entrapment } \\
\text { sites }\end{array}$ & $\begin{array}{l}\text { smallest not detectable, } \\
\text { hyalinised }\end{array}$ & $\begin{array}{l}\text { smallest only seen on } \\
\text { EM, intact and ruptured } \\
\text { CMBB }\end{array}$ & up to $1 / 2 \mathrm{RPE}$ cell high & $\begin{array}{l}\text { not found in eyes with } \\
\text { many drusen }\end{array}$ \\
\hline \multirow[t]{4}{*}{ Amorphous } & all hyalinised stain red on $\mathrm{P}-\mathrm{M}$ & $\begin{array}{l}\text { all amorphous electron } \\
\text { dense }\end{array}$ & & may be found in all eyes \\
\hline & (i) iridescent plaques & $\begin{array}{l}\text { all amorphous electron } \\
\text { dense }\end{array}$ & up to $10 \mu \mathrm{m}$ & \\
\hline & $\begin{array}{l}\text { (ii) globular drusen root-like } \\
\text { extensions }\end{array}$ & $\begin{array}{l}\text { all amorphous electron } \\
\text { dense }\end{array}$ & $\begin{array}{l}\text { all sizes may reach } \\
\text { clinical size }>30 \mu \mathrm{m}\end{array}$ & \\
\hline & $\begin{array}{l}\text { (iii) microdrusen over which } \\
\text { small globular drusen may } \\
\text { develop }\end{array}$ & $\begin{array}{l}\text { all amorphous electron } \\
\text { dense }\end{array}$ & $\begin{array}{l}\text { small } 1-2 \mu \mathrm{m} \text { form } \\
\text { rows up to } 10 \mathrm{RPE} \\
\text { cells in length }\end{array}$ & $\begin{array}{l}\text { found in eyes with many } \\
\text { drusen }\end{array}$ \\
\hline Mixed & $\begin{array}{l}\text { hyalinised heterogeneous stain } \\
\text { on } \mathrm{P}-\mathrm{M}\end{array}$ & $\begin{array}{l}\text { entrapment site material } \\
\text { with amorphous material }\end{array}$ & $\begin{array}{l}\text { maximum: } 30 \mu \mathrm{m} \\
\text { diameter up to } 1 \mathrm{RPE} \\
\text { cell high }\end{array}$ & $\begin{array}{l}\text { not found in eyes with } \\
\text { many drusen }\end{array}$ \\
\hline
\end{tabular}

$\mathrm{LM}=$ light microscopy $; \mathrm{EM}=$ transmission electron microscopy $\mathrm{CMBB}=$ coated membrane bound bodies; RPE = retinal pigment epithelium; P-M = Picro-Mallory stain.

large $(>20)$ numbers of drusen including two eyes from one patient, aged 60 , in whom the whole posterior pole of both eyes was studded with masses of small hard drusen. ${ }^{10}$ Although eyes with low and moderate numbers of drusen, the sequence of events in the development of drusen was most clearly established from the nine eyes with significant numbers of drusen. drusen in all stages of evolution were seen in The drusen in groups 1 and 2 were similar and
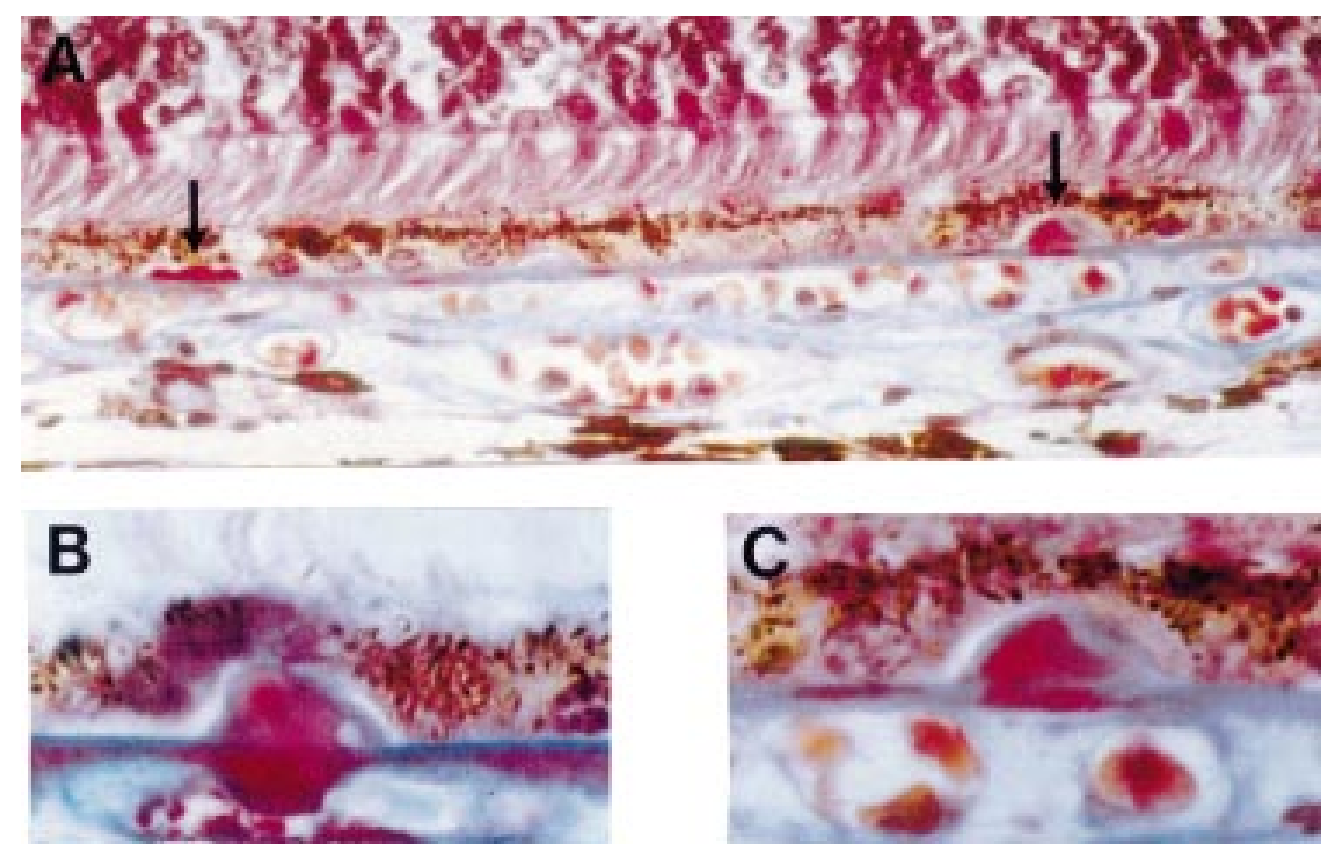

Figure 3 Preclinical hyalinised drusen formation in eyes with normal fundal appearance. (A) Left arrow shows row of three drusen, all less than half the height of an RPE cell. Right arrow shows single drusen one RPE cell high; (B) note the "root-like" extension of the hyalinisation into the outer collagenous zone; $(C)$ higher magnification of right drusen shown in (A). Note the regions of blue and red staining within the drusen. (A) and (C) a 42 year old man, vision 6/6, (B) a 75 year old man, vision 6/6. Picro-Mallory stain $(A) \times 300,(B)$ and $(C) \times 500$. 


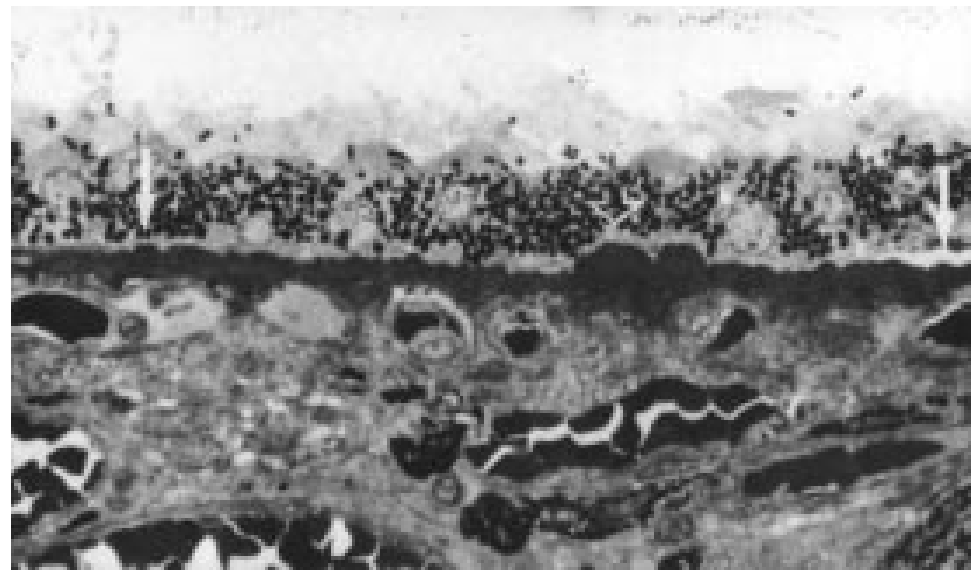

Figure 4 Preclinical small globular drusen and microdrusen. Microdrusen each around 1-2 $\mathrm{mm}$ in size forming a row (between arrows) of around 125-150 $\mu \mathrm{m}$. Open arrow marks a cluster of two small preclinical drusen. A 74 year old man with significant numbers of small hard drusen and drusen clusters, vision 6/6. A $0.5 \mu \mathrm{m}$ plastic section methylene blue, $\times 420$. tiny plaques in Bruch's membrane, small hyalinised globular deposits, or microdrusen occurring singly or in a row.

The first drusen related change to appear on LM were plaques or focal patches of thickened hyalinised Bruch's membrane around one RPE cell in diameter. These stained red with the picro-Mallory method, and had an iridescent appearance, noted best on racking the microscope up and down, which allowed them to be distinguished from the normal patchy hyalinisation which is seen from the fifth decade.

Drusen were first seen as tiny deposits on the inner surface of an iridescent plaque (Fig 3) Globular in shape, usually single, sometimes multiple, and often beneath a single RPE cell, they had a dense hyalinised appearance on LM staining either red, blue, or both with the picro-Mallory method. In many cases, the hyalinisation extended into the outer collagenous zone, indenting a choroidal capillary or extending down an intercapillary pillar, giving the appearance of "roots" beneath the drusen (Fig 3B). A range of sizes was seen. When small, <1 RPE cell in diameter (6-14 $\mu \mathrm{m})$ and up to half the height of an RPE cell $(6 \mu \mathrm{m})$, they displaced the base of the overlying RPE cell but were too small to elevate the took several forms:
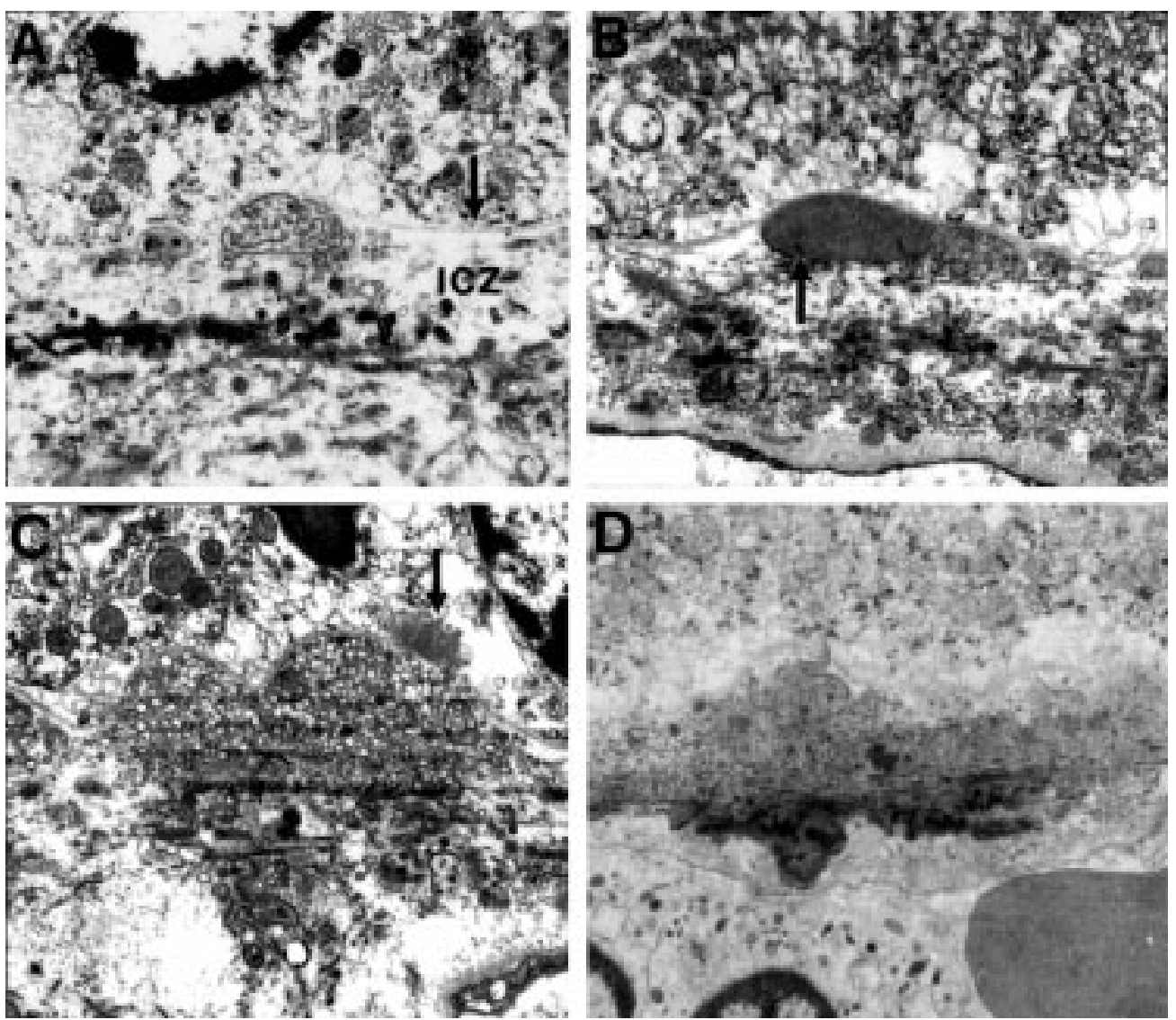

Figure 5 Preclinical drusen composed of entrapment sites, $(A)$ and (B) only detectable on EM. (A) Intact (left) and ruptured (right) coated membrane bound bodies $(C M B B)$ situated between the inner collagenous zone (icz) and basement membrane of the RPE (arrow). The ruptured CMBB have released their contents into the underlying collagenous zones. (B) Amorphous material that appears to be derived from the rupture or breakdown of CMBB. Arrow points to fragments of CMBB. (C) Entrapment site composed predominantly of vesicular material which is also present in the collagenous zones. Arrow points to a patch of BLD over the drusen. (D) Entrapment site composed of ruptured CMBB. Note the electron dense amorphous material in the outer collagenous zone giving the appearance of a root-like extension beneath the drusen similar to Figure 1 (B). (A), (B), (C) A 60 year old man with normal fundus appearance, vision 6/6. (D) A 43 year old man with normal fundal appearance, vision 6/6. $(A) \times 8880,(B) \times 9700,(C) \times 8000,(D) \times 6250$. 


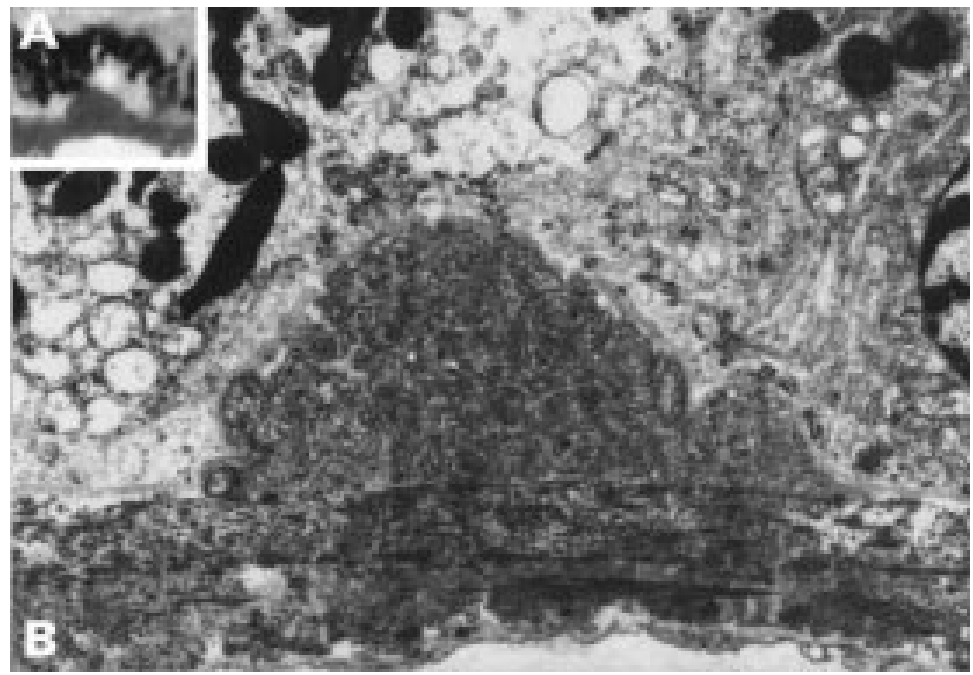

Figure 6 Preclinical drusen, entrapment site. This drusen appeared hyalinised on light microscopy (inset $A$ ) but EM (B) shows that it is an entrapment site composed of coated membrane bound bodies. A 50 year old man with normal fundal appearance, vision 6/6. (A) $\times 500,(B) \times 5600$.

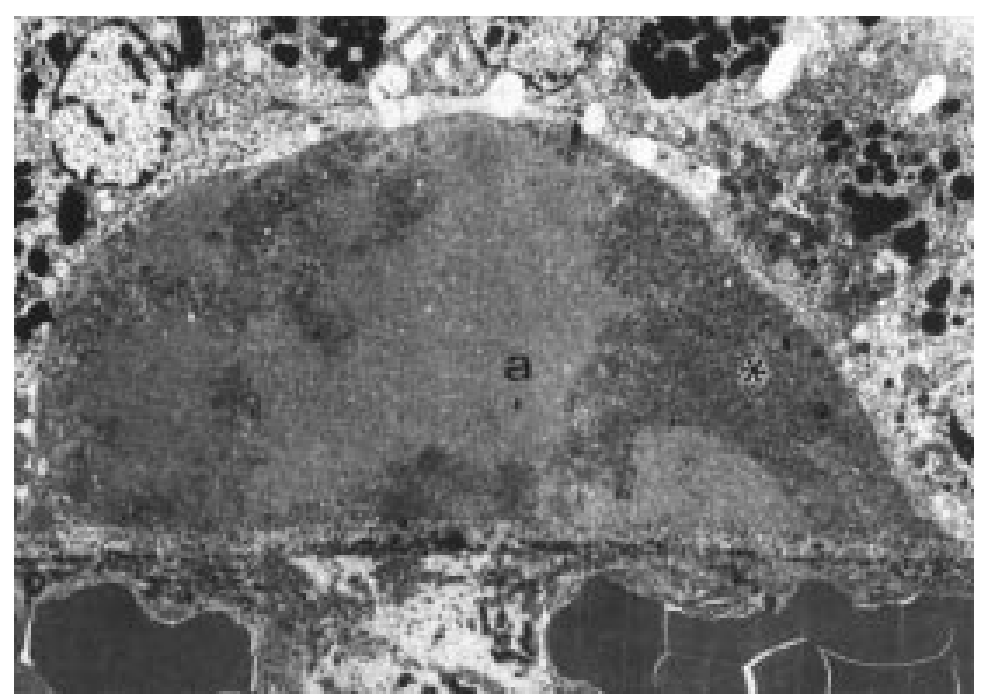

Figure 7 Preclinical drusen of mixed composition. EM shows an entrapment site of coated membrane bound bodies (asterisk) which has enlarged by the addition of amorphous material (a). This drusen would stain heterogeneously on LM with picro-Mallory. A 58 year old man with scattered small hard drusen, vision $6 / 6 . \times 3500$

apical cell border (Fig 3A left). However, the $\mathrm{RPE}$ cells overlying larger drusen of height equal to or more than one cell were displaced and attenuated (Fig 3B and 3C). They gradually enlarge, eventually reaching the size of a clinical drusen $(>30 \mu \mathrm{m})$.

A distinct finding were small (1-2 $\mu \mathrm{m}$ diameter) rounded elevations of a dense hyalinised appearance staining red with the picro-Mallory method which were termed microdrusen (Figs 4 and 9). In eyes with many drusen they were a universal feature, commonly forming rows up to $10 \mathrm{RPE}$ cells in length, and in places forming a continuous layer. On EM the microdrusen were composed of extremely dense amorphous material. Although more electron dense than the surrounding Bruch's membrane, the structure of the underlying collagenous zones was still evident. Small globular drusen showed a tendency to cluster and frequently these clusters formed over a row of microdrusen which appeared to pass beneath them.
While on LM all these early deposits had a hyalinised appearance, they could be distinguished on EM into two forms. Some were composed on EM of amorphous electron dense material similar to the microdrusen. But another form, which we have termed entrapment sites was composed of intact and ruptured (Fig 5A right and left) $\mathrm{CMBB}$ similar to those that accumulate within the outer collagenous zone of the aging Bruch's membrane. ${ }^{14}{ }^{15}$ These CMBB contained coated vesicle-like bodies, dense granules (Fig 5A), amorphous material (Fig 5B), and electron lucent droplets (Fig 5C). In some entrapment sites, the CMBB had ruptured, appearing to release their vesicular contents into the underlying collagenous zones (Fig 5A, 5C). Rarely, there was some association with electron dense plaques or root-like extensions (Fig 5D), as seen more commonly beneath small hyalinised drusen (Fig 3B). Entrapment sites were seen in eyes with only occasional drusen: they were not a feature of the six eyes (three patients) with large numbers of drusen which were examined by EM: only in one of these eyes was a single preclinical drusen with entrapment sites found, all other preclinical drusen deposits detected were of the amorphous type. Entrapment sites appear "trapped" between an elevated RPE basement membrane and collagen fibrils of the inner collagenous zone (Fig 5). Although the smallest entrapment sites (Fig 5A and B) were only detectable on EM, larger ones (Fig 6) were also seen on LM appearing as small hyalinised deposits. Pure entrapment sites were less than half the height of an RPE cell and were subclinical. Some larger drusen deposits, generally up to one RPE cell in height and 30 $\mu \mathrm{m}$ in diameter with the largest seen being a three drusen cluster of $36 \mu \mathrm{m}$ height and 325 $\mu \mathrm{m}$ diameter, were of mixed composition on EM (Fig 7), and appear to be formed by the addition of amorphous material and entrapment site material which lie in different regions within the drusen. These mixed drusen stained in a heterogeneous fashion with the picroMallory method, the denser amorphous material staining red and the more dispersed entrapment material staining blue (Fig 3C). Early preclinical drusen deposits seen on LM were therefore distinguishable on EM into either those consisting of amorphous material only, entrapment sites, or entrapment sites enlarged by amorphous material.

\section{CLINICAL DRUSEN ( $>25 \mu \mathrm{m}$ IN SIZE)}

Drusen larger than two RPE cells in diameter or 25-30 $\mu \mathrm{m}$ were clinically identifiable (Fig 8). Only a few clinical drusen in each eye were composed of mixed entrapment site material and amorphous material. On histopathology, most clinical drusen had a hyalinised appearance and by EM, an amorphous electron dense structure (Fig 9). They showed a tendency to cluster and there was a continuous gradation of size, the majority being $25-63 \mu \mathrm{m}$ in size, suggesting that they were being formed continuously. They were seen clinically as small hard drusen, yellowish with sharp borders, and with 

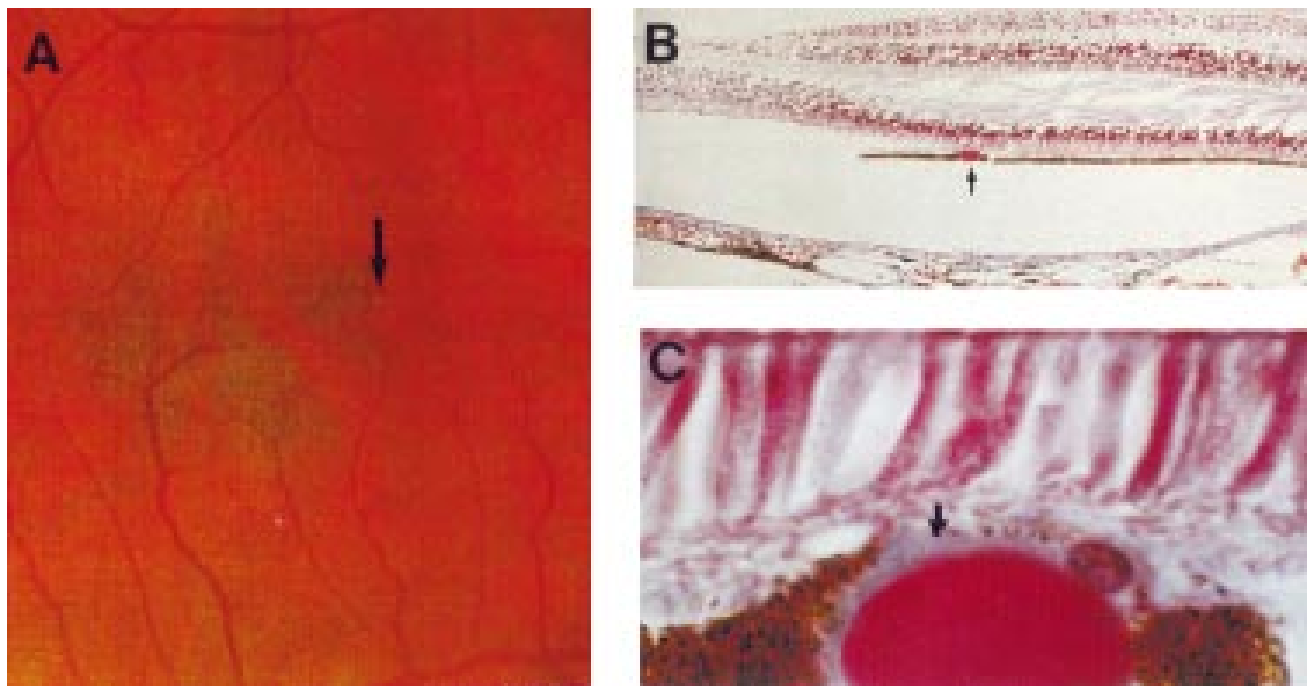

Figure 8 Smallest drusen detectable clinically. (A) Colour fundus photograph showing small hard drusen near the fovea (arrow). (B) LM section through fovea showing hyalinised drusen (arrow); (C) high power LM. The drusen measures 30 $\mu m$ in diameter. Note the blue staining BLD (arrow) over the surface of the drusen. The overlying RPE cells are displaced and attenuated. Right eye of 71 year old man, vision 6/6. (B) and (C) picro-Mallory, (B) $\times 75$. (C) $\times 500$.

bright early hyperfluorescence on fluorescein angiography.

Drusen appeared to enlarge by incorporation of several neighbouring deposits. Most drusen greater than $63 \mu \mathrm{m}$ in size had a lobulated appearance on LM suggesting that they were formed by enlargement and fusion of a cluster of drusen. Between single or clusters of clinical drusen were smaller subclinical drusen formed in relation to rows of microdrusen. The largest hyalinised drusen seen was $250 \mu \mathrm{m}$ diameter.

On LM the hyalinised contents of most drusen over $63 \mu \mathrm{m}$ became paler staining less intensely, beginning from the base (Fig 10A). On EM, the drusen showed a greater or lesser degree of dispersion of the contents leaving a rim of apparently firmer amorphous material at the apex (Fig 10B). Once this rim was lost,

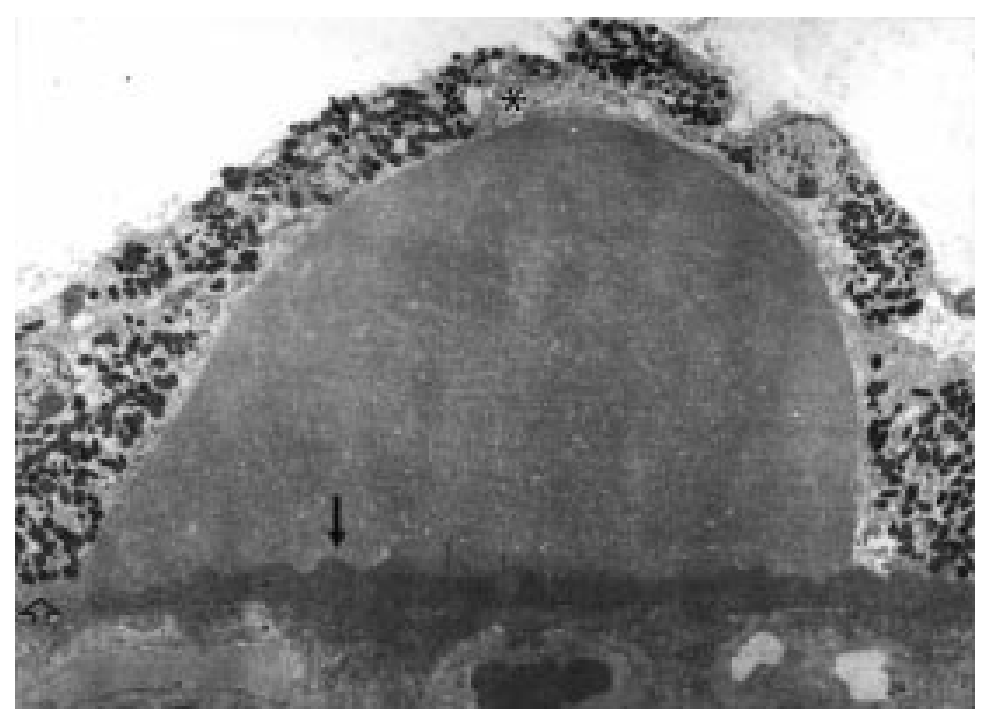

Figure 9 Clinical drusen measuring $60 \mu \mathrm{m}$ in diameter. Note that the hyalinised drusen has formed over a row of dense microdrusen (arrow) which continues beyond the drusen margin to the right. Compare with the normal Bruch's membrane on the left (open arrowhead). There is a small amount of BLD (asterisk) over the apex of the drusen. A 74 year old man with significant numbers of small hard drusen and drusen clusters, vision 6/6. $E M \times 1785$. the drusen lose their hard margins and spread out. Dispersal of the amorphous contents appeared to have resulted from a process resembling flocculation, the amorphous material condensing into particles surrounded by electron lucent spaces (Fig 10B).

\section{FATE OF CLINICAL DRUSEN}

Degenerative changes were seen in drusen over $>25 \mu \mathrm{m}$ in diameter in the form of outpouchings from the smooth globular surface of the drusen (Fig 11A). The incorporation of RPE pigment granules was seen in drusen from three eyes (Fig 11A and B). EM showed that this was due to an attenuated and degenerate overlying RPE, the contents of which were herniating through a break in the RPE basement membrane into the drusen (Fig 11C). Many drusen in group 2 eyes had a thin layer of early form BLD over the surface on EM.

Regression of drusen occurred in two ways. In some drusen, the dispersal process continued with extreme loss of material which gave rise to a moth eaten or washed out appearance. More commonly, and in older patients, the drusen contents became coarsely granular (Fig 12A): the youngest patient in whom a granular drusen was detected was 68 years old. As the drusen contents broke down, the basement membrane of the overlying RPE which had been stretched over the globular deposits, became infolded and collapsed onto Bruch's membrane (Figs 12B, C).

Drusen regression was accompanied by degenerative changes in the RPE with cell fallout and attenuation alternating with enlargement and hyperpigmentation of remaining cells (Fig 12A). Macrophage invasion was seen in one regressing drusen.

\section{Discussion}

In our study, we identified two methods of drusen formation. In the first, the initial event appeared to be the entrapment of coated membrane bound bodies between the basement 

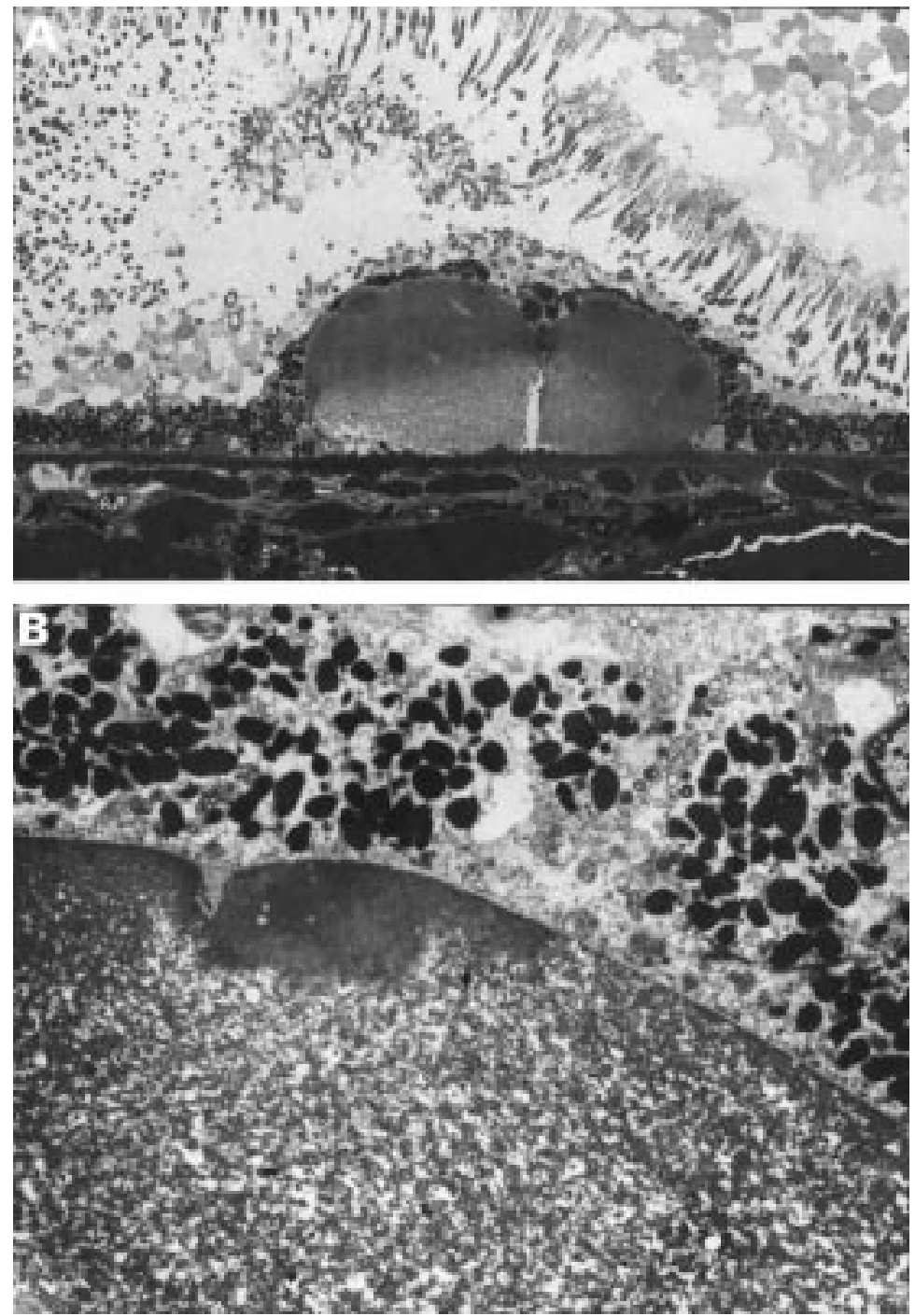

Figure 10 Dispersal of hyalinised clinical drusen. (A) The contents of this cluster of two drusen appear paler, beginning from the base. Note the row of dense microdrusen lying beneath the drusen. (B) On EM there is dispersal of the amorphous contents giving a flocculant appearance. A rim of amorphous material remains over the apex. A 74 year old man with significant numbers of small hard drusen and drusen clusters, vision 6/6. (A) 0.5 4m plastic section methylene blue, $\times 300,(B) \times 3690$.

membrane of the RPE and the collagen fibrils of the inner collagenous zone. These entrapment sites, identified on EM, may enlarge by the addition of amorphous material to form clinically visible small hard drusen. Although of similar composition to the CMBB that accumulate in the inner and outer collagenous zones in normal aging, ${ }^{16}{ }^{17}$ the entrapment does not appear to be due to excessive deposition since Bruch's membrane was only partially filled with age related deposits. Rather, it is likely that the CMBB, thought to be released from the basal plasma membrane of the RPE, are unable to enter the ICZ owing to the tight meshwork of collagen fibrils beneath them. ${ }^{18}$ We therefore prefer to call them entrapment sites rather than shedding sites, a term used by Feeney-Burns et al. ${ }^{15}$ We found no evidence that these deposits were formed by the process of evagination and pinching off of cytoplasm from the base of the RPE ${ }^{19}$ and in no section did we observe this material passing through the basement membrane of the RPE.
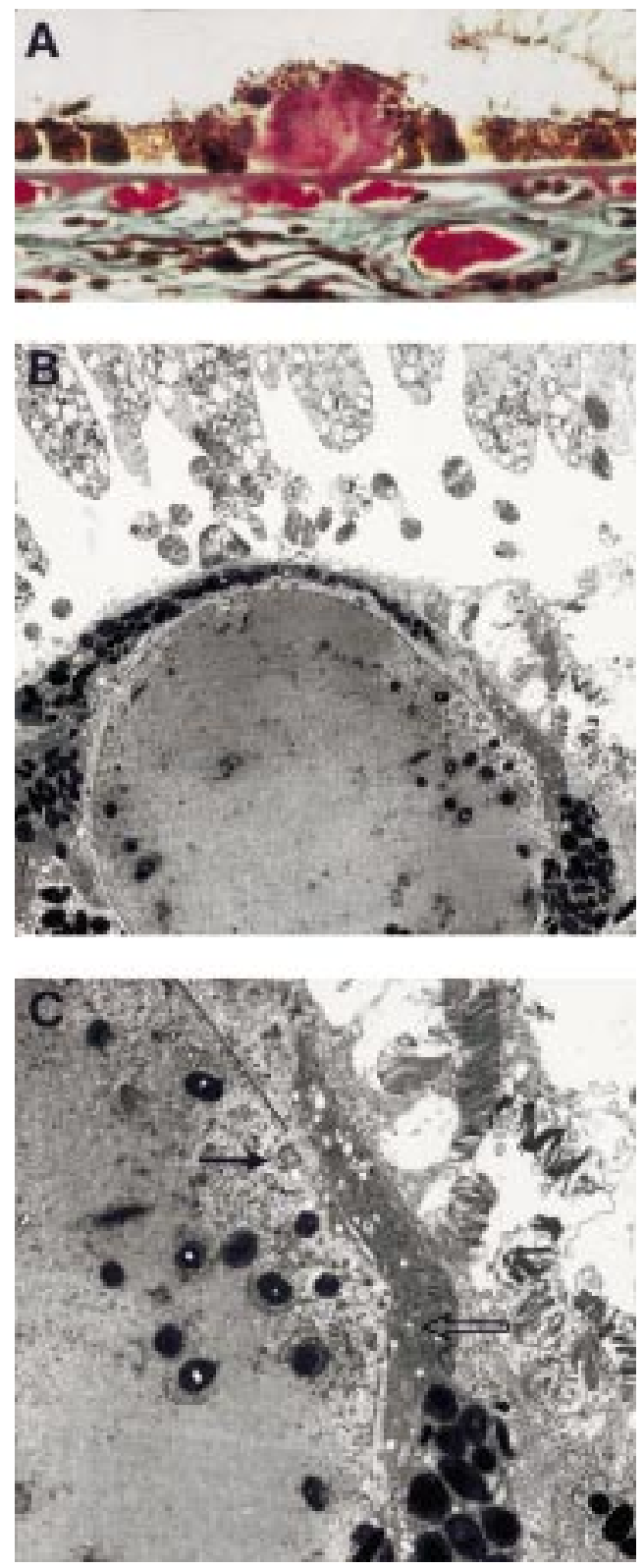

Figure 11 Degenerative changes in a clinical drusen. (A) LM shows outpouching from the smooth globular surface and pigment granules within the drusen; (B) low; and $(C)$ high magnification EM showing dark and condensed RPE cells overlying the drusen (open arrow). A fragment of degenerate RPE cytoplasm has herniated through a break in the RPE basement membrane into the drusen (arrow). A 73 year old man with less than five small hard drusen, vision 6/6. (A) Picro-Mallory $\times 300,(B) \times 2440,(C)$ $\times 10030$.

The membrane bound material found in entrapment sites should be distinguished from the membranous debris that accumulates on both surfaces of the basement membrane of the RPE in eyes with ARM; as basal mounds on the internal surface; and as a continuous layer on the external surface, called basal linear deposit by Green and Enger, ${ }^{7}$ which is the electron microscopic diagnostic hallmark of $\mathrm{ARM}^{10}$ (Table 2) - a continuous layer of BLD being the light microscopic hallmark of ARM. Build up of this debris leads to the formation of soft drusen which are pathognomonic of ARM. ${ }^{10}$ In contrast with the material found in entrapment sites, these coiled membranes are 

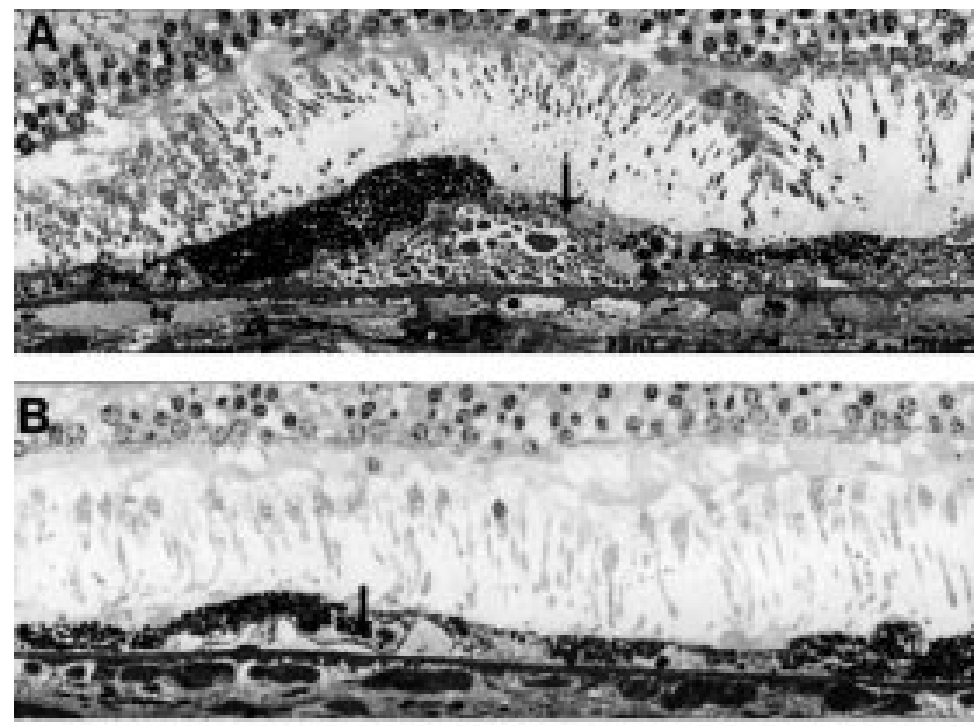

C

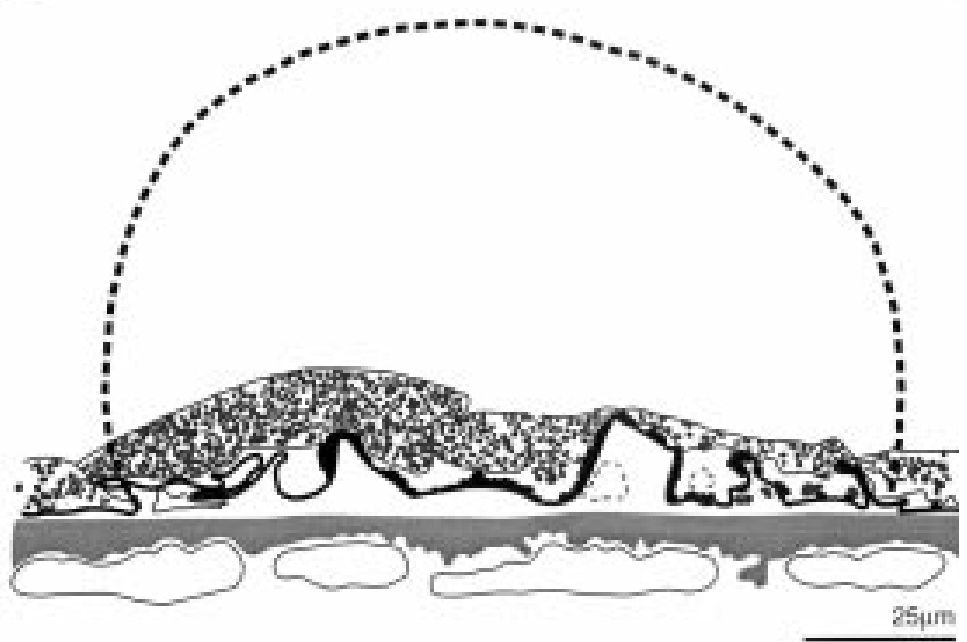

Figure 12 Drusen regression and disappearance. (A) The drusen contents have become coarsely granular. The overlying RPE is degenerate; note the large hyperpigmented cell (asterisk) next to an area of RPE attenuation and cell loss (arrow). (B) The RPE basement membrane appears collapsed and has become infolded (arrow) at the site where a granular drusen has disappeared; (C) overlay taken from EM of section shown in (B). The collapsed basement membrane has been measured. The broken line shows the drusen, 125 $\mu m$ in diameter, which would correspond to this length. Drusen of this size were seen in other sections from this eye. A 74 year old man with significant numbers of small hard drusen and drusen clusters, vision $6 / 6$. $0.5 \mu \mathrm{m}$ plastic section methylene blue, $\times 370$.

smaller and have the bilayered structure of lipids and are not coated.

Although the largest drusen composed only of entrapment site material was subclinical (less than the height of one RPE cell), nevertheless they can enlarge to clinical size $(>25-30 \mu \mathrm{m})$ through the addition of amorphous material. Only small numbers of these mixed drusen of clinical size were present in an eye, with even fewer detected in eyes with significant numbers of drusen. Entrapment sites may be seen in eyes of all ages and have also been detected in primate eyes, ${ }^{20}$ and are probably therefore part of normal aging metabolism rather than a pathogenic process. ${ }^{17}$ Their identification could explain why a few small hard drusen are common and may be detected clinically at all ages. ${ }^{21}$
In the second method of drusen formation, the earliest deposits were plaques and microdrusen of the hyalinised amorphous type resting as focal excrescences on the inner surface of a thickened Bruch's membrane, often with root-like extensions into both collagenous zones. Larger globular drusen develop over these changes. Entrapment site material was never found in the microdrusen nor in the overlying globular drusen suggesting that a different and pathological process is involved in this method of drusen formation. Larger drusen, up to $250 \mu \mathrm{m}$, appeared to be formed by the fusion of clusters of smaller deposits. ${ }^{10}$ In eyes with many drusen, the sequence of events appears to be as follows: (1) a row of microdrusen, composed of dense amorphous material, forms on the inner collagenous zone; (2) a overlying cluster of preclinical drusen develops; (3) one or more of these preclinical drusen enlarge to form the clusters seen clinically. A single drusen is formed by the incorporation of neighbouring smaller drusen; (4) as they enlarge the drusen contents disperse on LM, giving a flocculent appearance on EM. The dispersal commences at the base leaving a rim of denser amorphous material at the apex. This may be responsible for the finding by Mullins et $a l^{22}$ that only the cores of some hard drusen contain specific lectin binding glycoconjugates; (5) when the RPE over the drusen degenerates, the drusen regresses, the contents become coarsely granular on LM and the drusen may collapse. This sequence was best detected by study of the nine eyes with significant numbers of drusen in which, importantly, no entrapment sites were seen. In comparison with entrapment sites, therefore, we believe that these second type of early drusen represents precursors to pathological accumulations.

It is possible that the microdrusen play a pathogenic role in the later development of soft drusen. One soft drusen type, previously termed serogranular drusen, ${ }^{9}{ }^{10}$ clinically has a yellowish inspissated appearance, and fluoresces only late or not at all on fluorescein angiography. They commonly calcify as they regress and are often seen surrounding areas of geographic atrophy. On histopathology they have a granular structure with a row of microdrusen at their base. The presence of microdrusen and continuity with hyalinised drusen suggest that they may result from broken down clusters of hard drusen. The presence of microdrusen may also account for the marked increase in drusen numbers that can develop over time in previously normal appearing retina between existing drusen. Another postulated role for microdrusen may be in the formation of large confluent soft drusen or drusenoid detachments when occurring on a background of small hard drusen. One assumed pathogenic mechanism for these soft drusen is that they are formed by the addition of serous fluid which accumulates when fluid egress by the RPE pumping mechanism is delayed across Bruch's membrane rendered hydrophobic by an increase of lipids. ${ }^{1023}$ In older eyes with ARM, this barrier might be reinforced by the lipid membranous debris that 
accompanies the BLD. In eyes without BLD, it is possible that this hydrophobic barrier is formed by the rows of dense microdrusen.

It is stressed that this is not a quantitative paper addressing the incidence of drusen. The incidence of drusen detected clinically in our series is lower than that noted by recent epidemiological studies. ${ }^{1-4}$ This can be explained by differences in examination methods. These studies were based on drusen detection using $30^{\circ}$ stereoscopic photographs which can be expected to detect features two or three times as often as funduscopy. Fundus photography could not be performed in all eyes in our series however, owing both to the early date of many examinations (eyes were collected from 1967) and to the medical problems, most notably dementia and stroke, in many patients.

An important observation is that all the drusen detected in this group of 353 eyes without the diffuse deposits that mark ARM were of the small hard hyalinised variety or of their derivatives and that no soft indistinct drusen were seen. Our finding that only drusen larger than $30 \mu \mathrm{m}$ were detectable on funduscopy or fluorescein angiography confirms clinical definitions of minimum apparent drusen. ${ }^{124}$ Our study also clarifies the nature of the drusen in patients with massed drusen, the so called starry sky appearance. ${ }^{25}$ They have been called basal laminar drusen and attributed to a nodular thickening of the RPE basement membrane. ${ }^{25}$ The two eyes in our series with this appearance had large numbers of hard hyalinised drusen. Lipoidal degeneration of the $\mathrm{RPE}^{26}$ was found in only one eye with early BLD and preclinical hyalinised drusen. The changes found in Bruch's membrane, including electron lucent droplets and the development of BLD, confirm the findings of other workers. ${ }^{127}$

We observed two differing patterns of drusen regression and disappearance. In younger eyes, the hyalinised drusen contents gradually faded, giving the drusen a moth eaten appearance. In contrast, the hyalinised amorphous contents in older patients became coarsely granular. Drusen regression was associated with degenerative changes of the overlying RPE cells. Therefore, while the clinical prognostic implications of drusen disappearance are unknown, ${ }^{28}$ at least on the histopathological level drusen disappearance does not indicate a return to normality. Outpouchings were observed projecting from the surface of hyalinised or degenerating drusen which were confirmed on serial sections to be continuous with the parent drusen. This would account for the so called intracellular RPE drusen noted by previous observers. ${ }^{29}$

\section{Conclusion}

In eyes without diffuse deposits of BLD or membranous debris, all drusen histologically are of the hyalinised variety or of their derivatives. Ultrastructural examination would appear to identify two methods of drusen formation. The first are entrapment sites which may enlarge by the addition of amorphous material, and are seen mainly in eyes with only a few drusen. By contrast, in eyes with many drusen, early drusen form through a pathological accumulation of amorphous material only.

This finding of two methods of early drusen formation helps to clarify the question of the clinical significance of small hard drusen. The identification of entrapment sites, probably a normal and universal aging process, supports and helps to explain the findings of other authors who, from epidemiological ${ }^{28}$ and histopathological studies, ${ }^{70}$ consider the presence of a few small hard drusen to be normal and not to be a risk factor for the development of ARM. In contrast, in eyes with large numbers of small hard drusen, it is likely that the drusen represent pathological accumulations. These patients with masses of hard drusen are not currently classified as ARM, ${ }^{13}$ although both Bressler et $a l^{24}$ and Klein et al ${ }^{28}$ found that eyes with large areas of small hard drusen have an increased risk of developing soft indistinct drusen, a clinical marker of early ARM. Since these eyes, especially with the onset of pigment changes, are at risk of complications such as geographic atrophy and, more rarely, choroidal neovascularisation they could be considered to have a hard drusen maculopathy.

1 Bressler NM, Bressler SB, West SK, et al. The grading and prevalence of macular degeneration in Chesapeake Bay watermen. Arch Ophthalmol 1989;107:847-52.

2 Klein R, Klein BEK, Linton KLP. Prevalence of age-related maculopathy: the Beaver Dam Eye Study. Ophthalmology 1992;99:933-43.

3 Vinderling JR, Dielemans I, Hofman A, et al. The prevalence of age-related maculopathy in the Rotterdam study. Ophthalmology 1995:102:205-10.

4 Mitchell P, Smith W, Attebo K, et al. Prevalence of age-related maculopathy in Australia. The Blue Mountains Eye Study. Ophthalmology 1995;102:1450-60.

5 Sarks SH. Ageing and degeneration in the macular region: a clinicopathological study. Br f Ophthalmol 1976;60:32441

6 Sarks JP, Sarks SH, Killingsworth MC. Evolution of geographic atrophy of the retinal pigment epithelium. Eye 1988;2:552-77.

7 Green WR, Enger C. Age-related macular degeneration histopathologic studies; the 1992 Lorenz E Zimmerman Lecture. Ophthalmology 1993;100:1519-35.

8 Sarks SH. Changes in the region of the choriocapillaris in ageing and degeneration. 23rd Conc Ophthalmol, Kyoto 1979:228-38.

9 Sarks SH. Drusen and their relationship to senile macular degeneration. Aust F Ophthalmol 1980;8:117-30.

10 Sarks JP, Sarks SH, Killingsworth MC. Evolution of soft drusen in age-related macular degeneration. Eye 1994;8:
darks 269-283.

11 Gass JDM. Stereoscopic atlas of macular disease: diagnosis and treatment. 4th ed. St Louis: CV Mosby, 1997:10.

12 Loeffler KU, Lee WR. Basal linear deposit in the human macula. Graefes Arch Clin Exp Ophthalmol 1986;92:493501.

13 International ARM Epidemiological Study Group. An international classification and grading system for agerelated maculopathy and age-related macular degeneration. Surv Ophthalmol 1995;39:367-74.

14 Burns RP, Feeney-Burns L. Clinico-morphologic correlations of drusen of Bruch's membrane. Trans Am Ophthalmol Soc 1980;78:206-25.

15 Feeney-Burns L, Burns RP, Gao C-L. Age-related macular changes in humans over 90 years old. Am $\mathcal{f}$ Ophthalmol changes in humans

16 Hogan MJ. Bruch's membrane and disease of the macula: role of elastic tissue and collagen. Trans Ophthalmol Soc UK 1967;87:113-67.

17 Killingsworth MC. Age-related components of Bruch's membrane in the human eye. Graefes Arch Clin Exp Ophthalmol 1987;225:406-12.

18 Starita C, Hussain AA, Patmore A, et al. Localization of the site of major resistance to fluid transport in Bruch's membrane. Invest Ophthalmol Vis Sci 1997;38:762-7.

19 Ishibashi T, Patterson R, Oshnishi Y, et al. Formation of drusen in the human eye. Am f Ophthalmol 1986;101:34253.

20 Ishibashi T, Sorgente N, Patterson R, et al. Pathogenesis of drusen in the primate. Invest Ophthalmol Vis Sci 1986;27: drusen in the primate. Invest Ophthalmol Vis Sci 1986;27:

21 Coffey $\mathrm{AJH}$, Brownstein S. The prevalence of drusen in postmortem eyes. Am F Ophthalmol 1986;102:164-71. 
22 Mullins RF, Johnson LV, Anderson DH, et al. Characteristics of drusen-associated glycoconjugates. Ophthalmology 1997; 104:288-98.

23 Bird AC. Pathogenesis of retinal pigment epithelial detachment in the elderly; relevance of Bruch's membrane change. Eye 1991;5:1-12

24 Bressler NM, Munoz B, Maguire MG, et al. Five-year incidence and disappearance of drusen and retinal pigment epithelial abnormalities. Waterman study. Arch Ophthalmol 1995;113:301-8.

25 Gass JDM, Jallow S, Davis B. Adult vitelliform macular detachment occurring in patients with basal laminar drusen. Am f Ophthalmol 1985;99:445-59.

26 El Baba F, Green WR, Fleischmann J, et al. Clinicopathologic correlation of lipidization and detachment of the retinal pig- ment epithelium. Am f Ophthalmol 1986;101:576-83.

27 Curcio CA, Millican CI. Basal deposits in Bruch's membrane: distribution in aging and age-related maculopathy (ARM). Invest Ophthalmol Vis Sci 1988;39:S882.

28 Klein R, Klein BEK, Jensen SC, et al. The five-year incidence and progression of age-related maculopathy. Ophthalmology 1997;104:7-21.

29 Lerche W, Maslo KH. The fine structure of drusen in Bruch's membrane and in the pigment epithelium of human eyes. 23rd Conc Ophthalmol, Kyoto 1979:655-7.

30 Spraul CW, Grossniklaus HE. Characteristics of drusen and Bruch's membrane in postmortem eyes with agerelated macular degeneration. Arch Ophthalmol 1997;115: 267-73. 